\title{
Erratum to "Pneumococcal Conjugate Vaccines and Otitis Media: An Appraisal of the Clinical Trials"
}

\author{
Mark A. Fletcher and Bernard Fritzell \\ Pfizer Specialty Care Business Unit-Vaccines, International Scientific \& Clinical Affairs, Pfizer Inc, \\ 75668 Paris Cedex 14, France \\ Correspondence should be addressed to Mark A. Fletcher, mark.a.fletcher@pfizer.com \\ Received 27 July 2012; Accepted 9 August 2012
}

Copyright ( 2012 M. A. Fletcher and B. Fritzell. This is an open access article distributed under the Creative Commons Attribution License, which permits unrestricted use, distribution, and reproduction in any medium, provided the original work is properly cited.

Subsequent to the publication of the previous paper entitled "Pneumococcal Conjugate Vaccines and Otitis Media: An Appraisal of the Clinical Trials," scientific errors were discovered in Table 4. Therefore, an erratum was submitted with corrections to the table. 
TABle 4: Vaccine efficacy values in the long-term followup of PCV clinical trials with otitis media as an endpoint [3, 13]. Adapted with permission from Fletcher and Fritzell, 2007 Elsevier Ltd. All rights reserved [7].

\begin{tabular}{|c|c|c|}
\hline \multicolumn{3}{|c|}{ Follow-up clinical trials } \\
\hline & NCKP [3] & FinOM [13] \\
\hline Study vaccine & PCV7-CRM & PCV7-CRM \\
\hline Period & 1998-1999 & 1999-2001 \\
\hline Number & 27,754 & 756 \\
\hline Age & Until aged 3.5 years & Until aged $4-5$ years \\
\hline \multicolumn{3}{|c|}{ Clinical endpoints*: vaccine efficacy, \% (95\% CI) } \\
\hline \multirow{2}{*}{ Otitis media visits (NCKP) or episodes (FinOM) } & $\mathrm{PP} \quad 8(5-11)$ & $8(-2$ to 16$)$ \\
\hline & $7(5-9)$ & - \\
\hline \multicolumn{3}{|l|}{ Recurrent otitis media** } \\
\hline $3 / 4$ & $10(7-13)$ & $18(1-32) ; 50(15-71)^{\dagger}$ \\
\hline $5 / 6$ & - & - \\
\hline$\geq 10^{\ddagger}$ & $26(12-38)$ & - \\
\hline All tympanostomy-tube placements & $23(-10$ to 46$)$ & $\begin{array}{c}39(4-61)^{\S} ; 49(-7 \text { to } 76)^{\S \dagger} \\
44(19-62)^{\text {ๆ }} ; 63(28-81)^{\text {甲十 }}\end{array}$ \\
\hline Rate of AOM-related ambulatory visits & $8(5-10)$ & - \\
\hline Rate of antibiotic prescriptions for AOM & $6(4-7)$ & - \\
\hline
\end{tabular}

* See Table 1 for primary otitis media endpoint, otitis media definition, myringotomy criteria, and source of MEF in each study.

** Number of episodes in 6 months/number of episodes in 1 year.

† In children diagnosed with "chronic otitis media with effusion."

${ }^{\ddagger}$ Efficacy against 10 or more episodes within 6 months.

$\S$ Primary analysis set (see Section 3.5.2. FinOM vaccine trial).

"Secondary analysis set (see Section 3.5.2. FinOM vaccine trial).

Reported values are rounded to whole numbers; dash line indicates not reported.

CI: confidence interval; ITT: intent to treat; PP: per-protocol. 


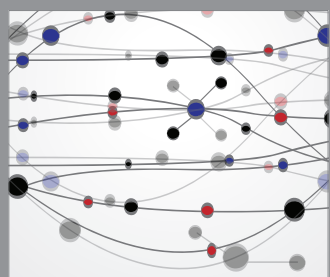

The Scientific World Journal
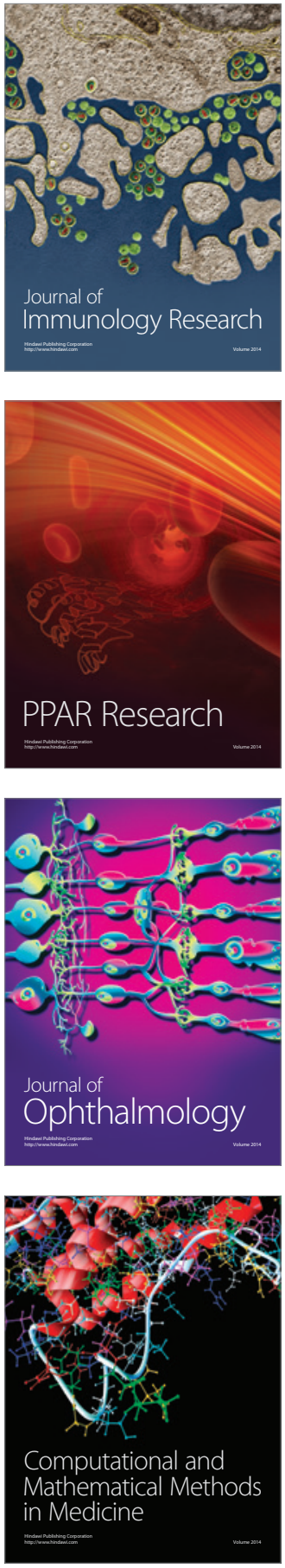

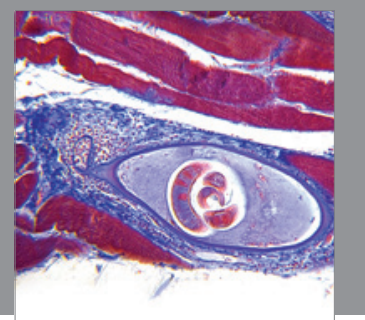

Gastroenterology

Research and Practice
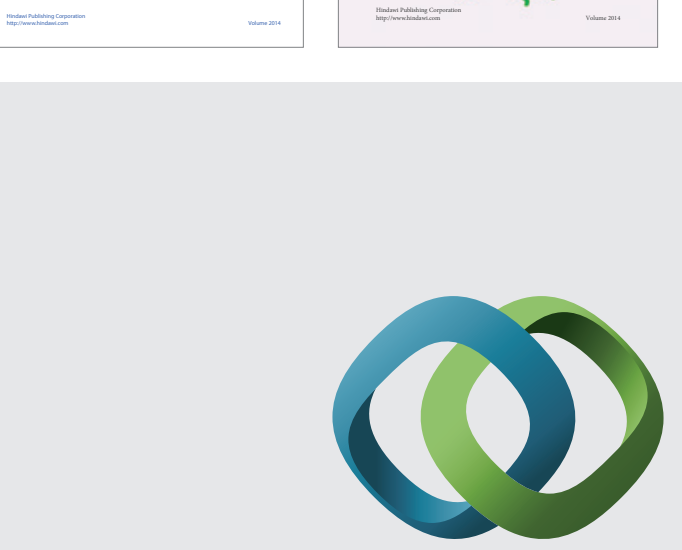

\section{Hindawi}

Submit your manuscripts at

http://www.hindawi.com
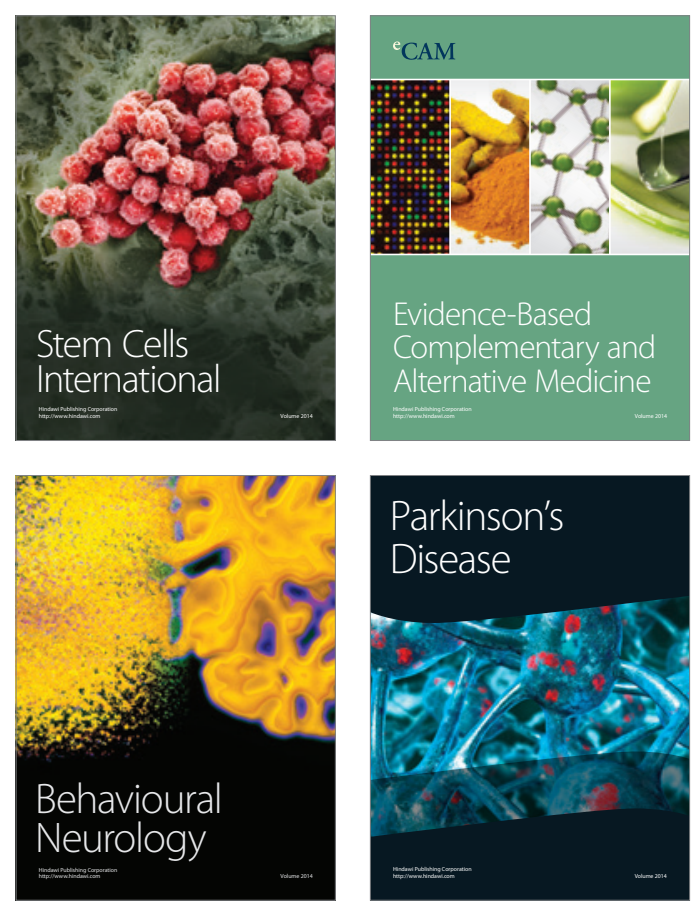

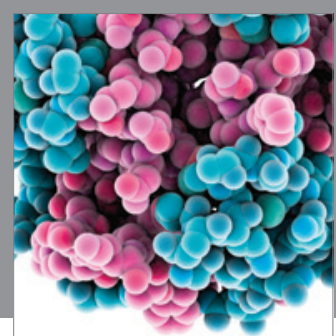

Journal of
Diabetes Research

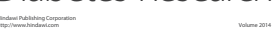

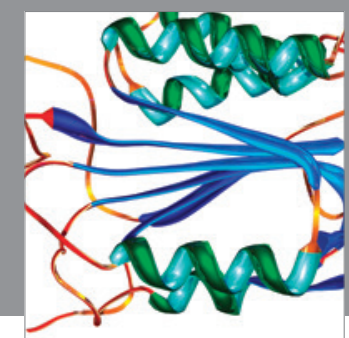

Disease Markers
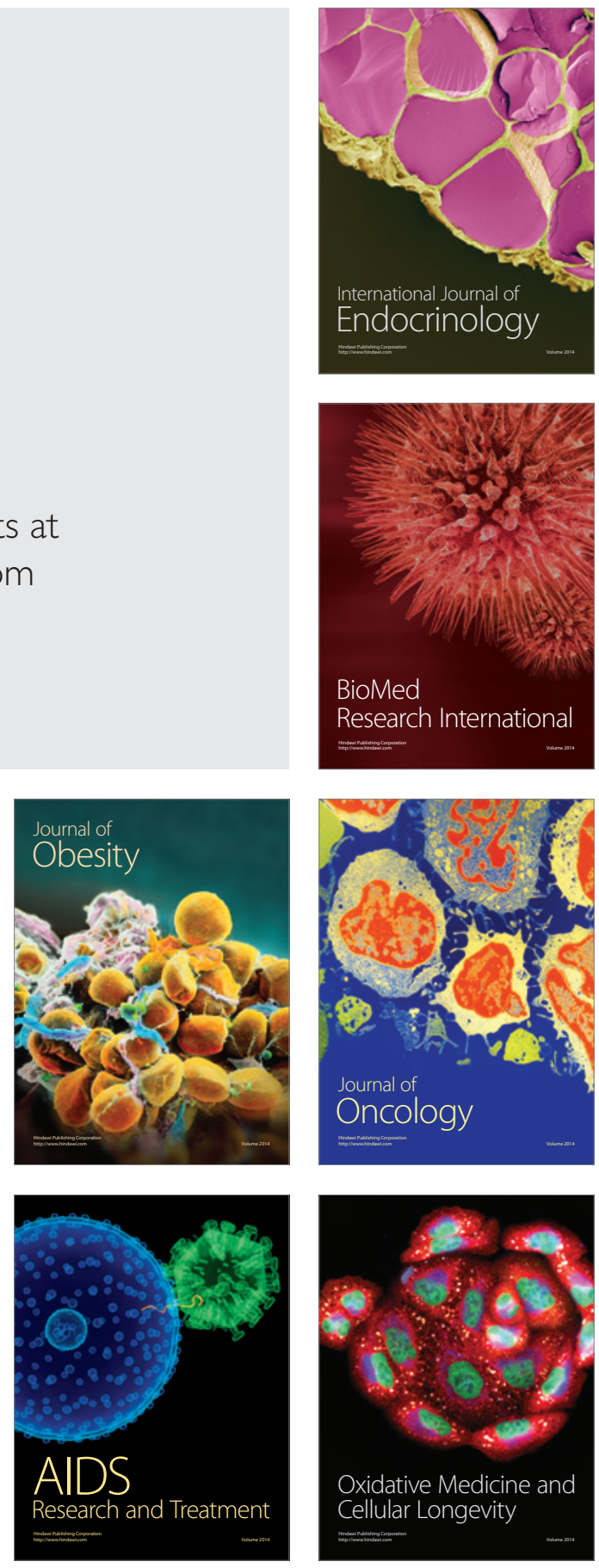